\title{
Pengembangan Worksheet Berbasis Keterampilan Proses dan Karakter Tema Lingkungan Sahabat Kita Kelas V SD
}

\author{
Nurul Hidayah*, Sugeng Eko Putro, Nur Ngazizah \\ Universitas Muhammadiyah Purworejo, Indonesia \\ *Coresponding Author: uyunurul086@gmail.com
}

Article History:

Received 2021-08-30

Revised 2022-01-02

Accepted 2022-01-22

DOI

10.31949/educatio.v8i1.1450

\begin{abstract}
Process and Character Skills in the worksheet still cannot be applied in learning. The objectives of this study are: (1) to determine the feasibility of a worksheet based on process and character skills, (2) to determine the practicality of a worksheet based on process and character skills in terms of student responses and the implementation of learning. This research is a development research using the ADDIE model (analyse, design, development, implementation, evaluation). The subject of the experiment was carried out on the fifth grade students of SD Negeri Kenteng. Data collection techniques used a questionnaire (questionnaire), observation, interviews, and document analysis. The data analysis technique used is qualitative and quantitative analysis. The results showed that the results of the validation of the feasibility of the worksheet obtained very feasible criteria, and the results of the validation obtained the Percentage Agreement obtained very reliable criteria. For practicality, in terms of the responses of students in the limited trial, they received a very good category, while the responses of students with the broad test obtained a very good category, while the results of the implementation of learning at meetings I, II, and III obtained a very good category. Thus, it can be concluded that a worksheet based on process and character skills is appropriate to use for the environmental theme of our friend in the fifth grade of elementary school

Keywords: character; process skills; worksheets.
\end{abstract}

\begin{abstract}
Abstrak
Keterampilan Proses dan Karakter dalam worksheet masih belum dapat diaplikasikan dalam pembelajaran. Tujuan penelitian ini yaitu: (1) mengetahui kelayakan worksheet berbasis keterampilan proses dan karakter, (2) mengetahui kepraktisan worksheet berbasis keterampilan proses dan karakter ditinjau dari respon peserta didik dan keterlaksanaan pembelajaran. Penelitian ini merupakan penelitian pengembangan dengan menggunakan model ADDIE (analyse, design, development, implementation, evaluation). Subjek uji coba dilakukan terhadap peserta didik kelas V SD Negeri Kenteng. Teknik pengumpulan data menggunakan angket (kuesioner), observasi, wawancara, dan analisis dokumen. Teknik analisis data yang digunakan adalah analisis kualitatif dan kuantitatif. Hasil penelitian menunjukkan bahwa hasil validasi kelayakan worksheet diperoleh kriteria sangat layak, dan hasil validasi mendapatkan Percentage Agreement memperoleh kriteria sangat reliabel. Untuk kepraktisan, ditinjau dari respon peserta didik pada uji coba terbatas mendapatkan kategori sangat baik, sedangkan respon peserta didik dengan uji luas memperoleh kategori sangat baik, adapun hasil keterlaksanaan pembelajaran pertemuan I, II, dan III memperoleh kategori sangat baik. Dengan demikian, dapat disimpulkan bahwa worksheet berbasis keterampilan proses dan karakter layak digunakan untuk tema lingkungan sahabat kita kelas V Sekolah Dasar

Kata kunci: karakter; keterampilan proses; worksheet.
\end{abstract}

\section{PENDAHULUAN}

Pembelajaran merupakan proses pemerolehan ilmu baik melalui pendidikan formal, pengalaman yang dihadapi, bahkan dari lingkungan peserta didik. Dalam pendidikan formal peserta didik memperoleh pembelajaran di sekolah di mana saat ini pembelajaran menggunakan kurikulum 2013. Kurikulum 2013 
merupakan salah satu kurikulum yang berlaku di dunia pendidikan saat ini, di mana proses pembelajarannya menggunakan model pembelajaran tematik. Kurikulum 2013 yang digunakan saat ini menekankan kompetensi yang seimbang yaitu antara pencapaian asepek kognitif/pengetahuan, afektif/sikap serta psikomotorik/keterampilan. Ketiganya harus dapat dikuasai oleh setiap peserta didik sebagai wujud keberhasilan dalam pembelajaran (Prasetyo, Rizki dkk. 2018:163). Kurikulum 2013 menggunakan model pembelajaran tematik.

Pembelajaran tematik adalah pembelajaran yang mengintegrasikan antara mata pelajaran satu dengan lainnya ke dalam sebuah tema tertentu (Anshory et al, 2018; Hakim, 2014; Wandini, 2017). Pembelajaran tematik terdiri dari beberapa muatan pembelajaran diantaranya Ilmu Pengetahuan Alam (IPA), Ilmu Pengetahuan Sosial (IPS), Bahasa Indonesia, Pendidikan Pancasila dan Kewarganegaraan (PPKn), Seni Budaya dan Prakarya (SBdP), dan Matematika. Matematika tidak termasuk dalam muatan pembelajaran tematik di kelas tinggi yaitu kelas IV, V, dan VI, namun berdiri sendiri. Pembelajaran tematik dikemas menggunakan muatan pembelajaran yang berhubungan dengan kegiatan pada kehidupan sehari-hari agar peserta didik dapat memperolah pengalaman belajar yang menarik, efektif, lebih bermakna serta menanamkan peserta didik untuk menjadi pibadi yang aktif, kreatif, dan inovatif. Salah satunya adalah pembelajaran Ilmu Pengetahuan Alama (IPA). Pembelajaran IPA di jenjang Sekolah Dasar memiliki peranan penting dalam pembelajaran IPA di jenjang-jenjang berikutnya, sebab pengetahuan awal siswa dimulai sejak dasar dan keberhasilannya mengikuti minat peserta didik untuk belajar IPA.

Pembelajaran IPA pada hakikatnya merupakan suatu upaya membelajarkan peserta didik untuk memahami meliputi: produk, proses dan sikap serta aplikasi IPA yang positif. Sesuai dengan tujuan pembelajaran IPA peserta didik menemukan pengetahuan dan pemahaman materi berdasarkan pengalaman dan belajar bersama di lingkungan sekitar peserta didik. Dalam pembelajaran peserta didik juga mampu untuk menggali sserta menemukan pengetahuan dengan aktif dan mandiri, sehingga peserta didik tidak hanya secara instan memperoleh pengetahuan hanya dari guru saja, tapi imajinasi dan kreatifitas, sikap dan ilmiah, dan mampu menerapkan pengetahuan yang dimilikinya dalam kehidupan sehari-hari (Pamungkas, Aji et. al, 2107: 119).

Kenyataannya di lapangan dalam pembelajaran IPA masih menggunakan metode yang berpusat pada guru (teacher centered), sehingga peserta didik belum mendapatkan pengalaman belajar yang menantang dan bermakna. Prestasi belajar IPA peserta didik di Indonesia pada survey PISA dan TIMSS yang rendah. Rendahnya prestasi belajar IPA siswa juga terungkap pada penelitian-penelitian terdahulu, sehingga perlu dilakukan upaya untuk meningkatkannya (Hasyda, 2020; Susilowati, 2017; Warsiki, 2018). Penelitian yang dilakukan, salah satunya disebabkan oleh faktor proses pembelajaran yang berpusat pada guru, tidak hanya itu, bahan ajar yang digunakan pun masih cenderung memberikan pengetahuan secara instan bahan ajar nya masih berorientsi dengan aspek kognitif saja, sehingga aspek afektif dan psikomotoriknya belum dikuasai oleh peserta didik. Pembelajaran diarahkan untuk menghafal, sehingga peserta didik minim pengaplikasian dan pemecahan masalah.

Keberhasilan pembelajaran tidak lepas dari adanya sarana dan prasarana dalam pembelajaran terutama bahan ajar. Bahan ajar merupakan kumpulan materi pembelajaran yang digunakan guru dan peserta didik dalam proses pembelajaran (Hakim, 2017). Bahan ajar harus ada dalam pembelajaran, agar dalam pembelajaran bisa berjalan dengan maksimal serta pembelajaran dapat hidup. Penelitian-penelitian terdahulu juga banyak yang berhasil meningkatkan hasil belajar siswa melalui pngembengan bahan ajar, diantaranya Asrizal et al (2017), Bujuri \& Baiti, (2018), Khairani et al (2017), dan Komalasari et al (2019). Berbeda dengan penelitian-penelitian tersebut, bahan ajar yang dikembangkan dalam penelitian ini berupa Worksheet dengan berbasis keterampilan proses dan karakter siswa.

Worksheet merupakan lembaran-lembaran yang dibukukan dan berisi tugas yang harus dikerjakan oleh peserta didik. Worksheet dikembangkan oleh guru sebagai fasilitator dalam pembelajaran, pada umumnya worksheet berisi mengenai tugas-tugas, praktikum, percobaan yang bisa dilakukan di rumah, materi untuk diskusi, portofolio serta dikemas dengan cara yang menarik dan tidak monoton agar pembelajaran dapat terarah. Worksheet memiliki kedudukan yang sangat penting dalam pembelajaran, sehingga dalam 
penyusunannya harus diperhatikan dengan baik, serta terstruktur agar dapat berfungsi dengan maksimal Di samping itu, worksheet juga harus disusun dengan sistematis, rinci, dan memenuhi syarat penyusunan yang baik serta memenuhi 3 ranah penilian, sehingga peserta didik dapat menguasai pembelajaran serta dapat meningkatkan keterampilan proses bagi peserta didik.

Keterampilan proses dalam penelitian ini merupakan kemampuan peserta didik untuk bisa berpikir lebih objektif dan kritis terhadap setiap hal yang ada disekitarnya terkhusus dalam proses belajar peserta didik (Sa'ria et al, 2021). Keterampilan proses disini mendorong peserta didik untuk lebih aktif, memperoleh pengetahuan dengan pengalaman yang dilakukannya sehingga dapat mendarah daging dan mengetahui konsep yang dilakukannya. Ketika masing-masing dari keterampilan proses peserta didik dapat menguasai, maka pembelajaran dapat terlaksana dengan maksimal serta tujuan pendidikan dapat tercapai dengan maksimal juga.

Pengambangan worksheet dalam penelitian ini juga berbasis karakter siswa. Karakter merupakan ciri khas yang yang dimiliki oleh suatu benda atau individu, yang mana ciri khas tersebut sudah mengakar pada kepribadian benda itu, serta mendorong seseorang untuk bertindak, bersikap, serta menanggapi / merespon sesuatu, dengan demikian karakter merupakan sikap penanaman yang di ajarkan sejak masih kecil sehingga hal itu dapat terbawa hingga dewasa kelak, karakter inilah yang akan membawa jati diri seseorang dalam kehidupan yang di jalaninya. Penerapan pendidikan karakter dapat dilakukan di mana saja dari lingkungan keluarga yang memiliki kontribusi penuh sebagai tempat pertama dalam penerapan pendidikan karakter. Salah satu dalam membentuk karakter siswa secara utuh (holistik) dengan memahami nilai-nilai karakter. Dalam menanamkan nilai-nilai karakter diperlukan upaya agar karakter yang dibentuk dapat berhasil. Adapun upaya yaitu mengembangkan siswa dengan memperhatikan aspek antara lain aspek fisik, emosi, kreativitas, dan intelektual. Semua itu dilakukan secara optimal (Murniyetti, 2016).

Berdasarkan penjelasan latar belakang yang telah dipaparkan, maka dilakukan penelitian ini bertujuan untuk (1) mengetahui kelayakan worksheet berbasis keterampilan proses dan karakter, (2) mengetahui kepraktisan worksheet berbasis keterampilan proses dan karakter ditinjau dari respon peserta didik dan keterlaksanaan pembelajaran.

\section{METODE PENELITIAN}

Penelitian ini menggunakan metode penelitian pengembangan atau Research and Devepoment (R\&D). Metode ini digunakan untuk menghasilkan sebuah produk. Tempat yang digunakan sebagai subjek penelitian dan pengembangan Worksheet berbasis Keterampilan Proses dan Karakter Tema Lingkungan Sahabat Kita Subtema 1 Manusia dan Lingkungan di SD Negeri Kenteng kecamatanBanyuurip Kabupaten Purworejo. Penelitian dilaksanakan dalam rentang waktu November 2020 sampai dengan bulan Juli 2021. Subjek uji coba penelitian yang digunakan adalah siswa kelas V SD Negeri Kenteng, Banyuurip, Purworejo tahun ajaran 2020/2021 yang terdiri dari 14 peserta didik.

Prosedur penelitian ini mengadaptasi model pengembangan ADDIE dari Robert Maribe Branch (2009:2), yaitu model pengembangan yang terdiri dari lima tahapan yaitu: tahap analysis (analisis) dilakukan dengan menganalisis kompetensi yang harus dikuasai oleh peserta didik secara riil diwujudkan dengan penentuan Standar Kompetensi, Kompetensi Dasar, dan Tujuan Pembelajaran. Tahap Design (perancangan) ini difokuskan pada tiga kegiatan, yaitu pemilihan materi sesuai dengan karakteristik peserta didik dan tuntutan kompetensi yang ingin dicapai, strategi pembelajaran, bentuk dan metode asessmen, serta evaluasi. Tahap Development (pengembangan), prosedur untuk yang dilakukan pada tahap develop adalah: 1) Membangun konten; 2) memilih atau mengembangkan bahan ajar penduklung; 3) mengembangkan panduan untuk peserta didik; 4) mengembangkan panduan untuk guru; 5) melakukan validasi ahli; 6) melakukan revisi sesuai dengan masukan para ahli dan dengan uji coba terbatas. Tahap Implementation (implementasi) Tahap implementasi terdapat dua prosedur, yaitu mempersiapkan guru dan mempersiapkan peserta didik. Tahap Evaluation (evaluasi) Tahap dilakukan untuk mengetahui respon dan keterlaksanaan pembelajaran. 
Teknik pengumpulan data yang digunakan dalam penelitian ini yaitu observasi, wawancara, dan angket. Instrumen penelitian yang digunakan pada penelitian ini yaitu lembar observasi, lembar wawancara, lembar angket.

\section{HASIL DAN PEMBAHASAN}

Berdasarkan hasil penelitian yang dilaksanakan di SD Negeri Kenteng dapat dijelaskan bahwa penggunaan media worksheet pada kelas $\mathrm{V}$ berbeda seperti kegiatan pembelajaran yang menggunakan LKS sebelumnya. Tahap I yang dilakukan sebelum memulai penelitian adalah membuat produk. Produk pengembangan worksheet dapat dilihat pada gambar 1 .

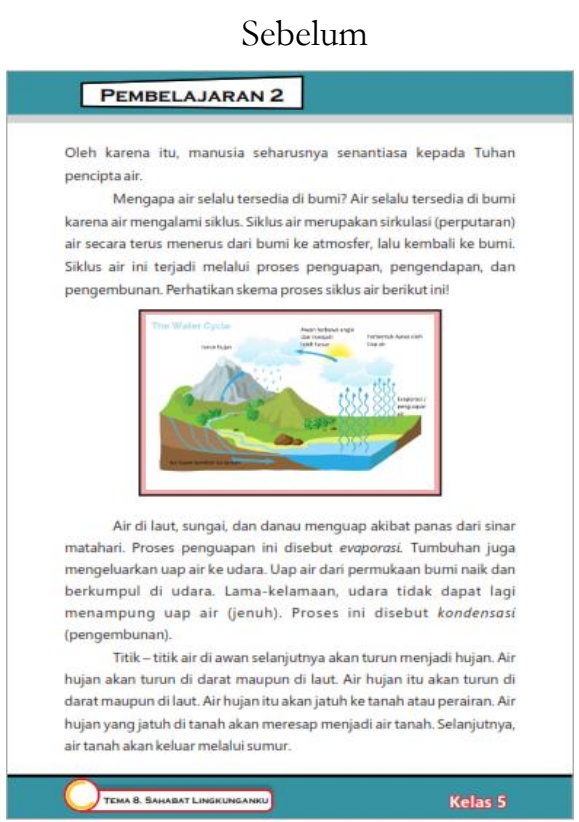

Belum adanya sumber di gambar yang di adopsi

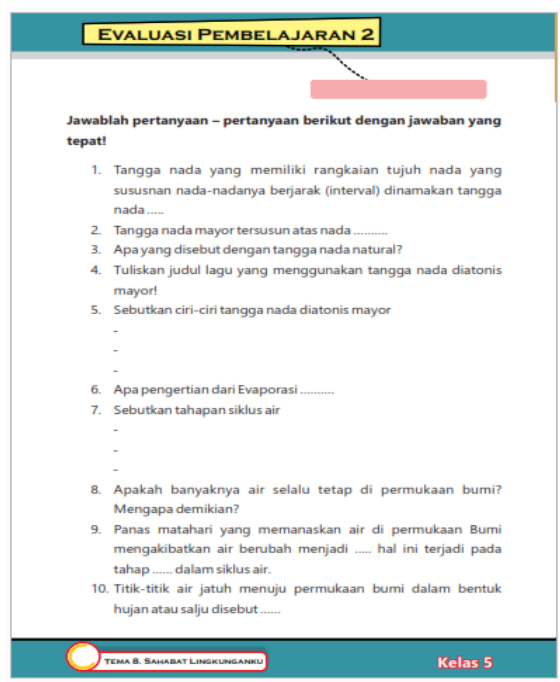

Belum ada evaluasi per KD di akhir pembelajaran

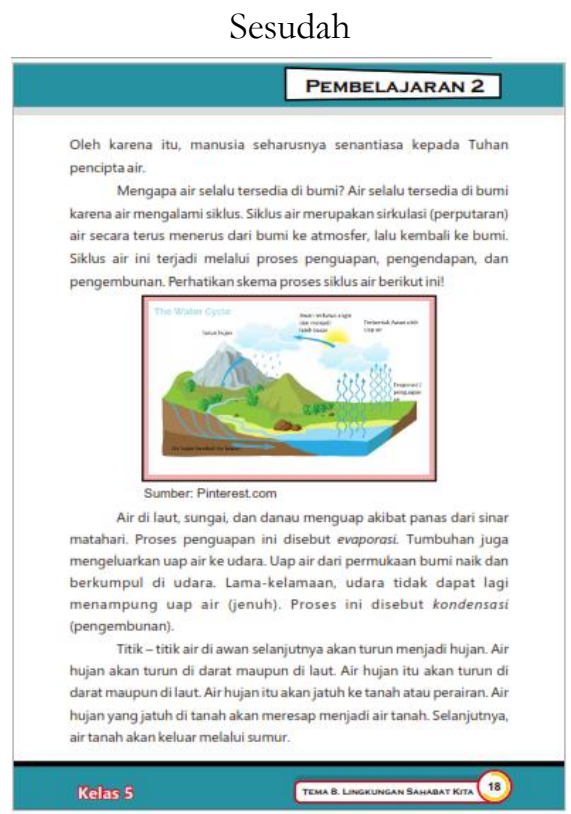

Ditambahkan sumber di gambar

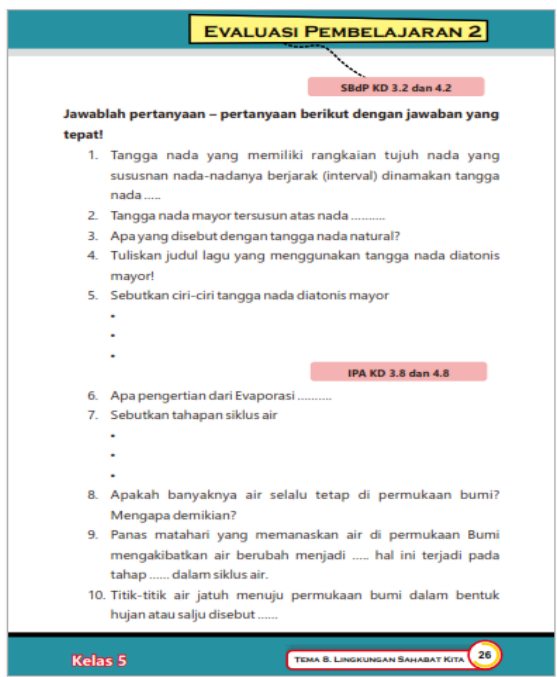

Sudah ada evaluasi per KD di akhir pembelajaran

Gambar 1. Produk pengembangan worksheet

Setelah worksheet dikembangkan selanjutnya bahan ajar worksheet masuk ketahap validasi. Pada tahap validasi akan divalidasi oleh 3 validator, antara lain ahli media, ahli materi, dan praktisi. Hasil dari validasi oleh 
ke-3 validator dapat dilihat pada tabel 2. Hasil validasi pada aspek kelayakan isi diperoleh jumlah skor 107 sehingga diperoleh presentase 89,1\% dan nilai 3,56 dengan kriteria sangat layak. Aspek kebahasaan diperoleh jumlah skor 12 sehingga memperoleh presentase $75 \%$ dan nilai 3 dengan kriteria layak.

Tabel 2. Data hasil validasi worksheet berbasis keterampilan proses dan karakter

\begin{tabular}{llcccccl}
\hline \multirow{2}{*}{ No } & \multirow{2}{*}{ Aspek yang dinilai } & \multicolumn{2}{c}{ Skor } & \multirow{2}{*}{ Jumlah } & \multirow{2}{*}{ Validasi } & \multirow{2}{*}{ Nilai } & \multirow{2}{*}{ Kriteria } \\
\hline 1. & Kelayakan isi & 55 & 52 & 107 & $89,1 \%$ & 3,56 & Sangat layak \\
2. & Kebahasaan & 7 & 7 & 14 & $87,5 \%$ & 3,5 & Sangat layak \\
3. & Penyajian & 6 & 7 & 12 & $75 \%$ & 3,25 & Layak \\
4. & Tampilan enyeluruh & 16 & 14 & 30 & $93,8 \%$ & 3,75 & Sangat layak \\
5. & Anatomi Worksheet & 11 & 12 & 23 & $95,8 \%$ & 3,8 & Sangat layak \\
\multicolumn{2}{r}{ Rata-rata } & & & 37,2 & $88,24 \%$ & 3,57 & Sangat layak \\
\hline
\end{tabular}

Aspek penyajian diperoleh jumlah skor 14 sehingga diperoleh presentase 87,5\% dan nilai 3,5 dengan kriteria sangat layak. Aspek tampilan menyeluruh diperoleh jumlah skor 30 dengan memperoleh presentase 93,8\% dan nilai 3,75 dengan kriteria sangat layak. Aspek anatomi worksheet diperoleh jumlah skor 23 sehingga diperoleh presentase $95,8 \%$ dan nilai 3,8 dengan kriteria sangat layak.

Tabel 3. Hasil Respon Peserta Didik Pada Uji Coba Terbatas Terhadap Worksheet

\begin{tabular}{clccc}
\hline No. & \multicolumn{1}{c}{ Aspek } & Skor & Persentase & Kriteria \\
\hline 1. & Tampilan Worksheet & 99 & $88,39 \%$ & Sangat Baik \\
2. & $\begin{array}{l}\text { Penerapan Worksheet berbasis } \\
\text { keterampilan proses dan karakter } \\
\quad \text { Rata-rata }\end{array}$ & 548 & $88,9 \%$ & Sangat Baik \\
& & & $88,6 \%$ & Sangat Baik \\
\hline
\end{tabular}

Berdasarkan data hasil respon peserta didik pada uji coba terbatas memperoleh hasil pada masingmasing indikator dalam instrument respon peserta didik terhadap worksheet yaitu aspek tampilan mendapatkan presentase 88,39 \% dengan kriteria sangat baik. Penerapan Worksheet berbasis keterampilan proses dan karakter mendapatkan presentase $88,9 \%$ dengan kriteria sangat baik.

Tabel 4. Hasil Respon Peserta Didik Pada Uji Coba Terbatas Terhadap Worksheet

\begin{tabular}{clccc}
\hline No & \multicolumn{1}{c}{ Aspek } & Skor & Persentrase & Kriteria \\
\hline 1. & Tampilan Worksheet & 102 & $91,1 \%$ & Sangat baik \\
2. & $\begin{array}{l}\text { Penerapan worksheet berbasis keterampilan } \\
\text { proses dan karakter }\end{array}$ & 557 & $90,4 \%$ & Sangat baik \\
\multicolumn{2}{c}{ Rata-rata } & & $90,75 \%$ & Sangat baik \\
\hline
\end{tabular}

Berdasarkan data hasil respon peserta didik pada uji coba luas memperoleh hasil pada masing-masing indikator dalam instrument respon peserta didik terhadap worksheet dibagi menjadi 2 aspek yaitu aspek tampilan Worksheet mendapatkan presentase $91,1 \%$ dengan kriteria sangat baik. Penerapan Worksheet berbasis keterampilan proses dan karakter mendapatkan presentase 90,4\% dengan kriteria sangat baik.

Tabel 5. Hasil Keterlaksanaan Pembelajaran .

\begin{tabular}{|c|c|c|c|c|c|c|c|}
\hline \multirow{3}{*}{ No } & \multirow{3}{*}{ Aspek } & \multicolumn{6}{|c|}{ Pertemuan } \\
\hline & & \multicolumn{2}{|c|}{ I } & \multicolumn{2}{|c|}{ II } & \multicolumn{2}{|c|}{ III } \\
\hline & & 1 & 2 & 1 & 2 & 1 & 2 \\
\hline 1. & Kegiatan pembuka & 21 & 20 & 23 & 24 & 23 & 24 \\
\hline 2. & Kegiatan inti & 30 & 29 & 33 & 31 & 34 & 32 \\
\hline 3. & Kegiatan penutup & 17 & 17 & 19 & 19 & 19 & 19 \\
\hline \multicolumn{2}{|c|}{ Jumlah } & 68 & 66 & 75 & 74 & 76 & 75 \\
\hline \multicolumn{2}{|c|}{ Persentase (\%) } & \multicolumn{2}{|c|}{$85,1 \%$} & \multicolumn{2}{|c|}{$99,33 \%$} & \multicolumn{2}{|c|}{$99,34 \%$} \\
\hline \multicolumn{2}{|c|}{ Kriteria } & \multicolumn{2}{|c|}{ Sangat Baik } & \multicolumn{2}{|c|}{ Sangat Baik } & \multicolumn{2}{|c|}{ Sangat Baik } \\
\hline
\end{tabular}


Hasil keterlaksanaan pembelajaran dari dua observer pada setiap pertemuan menunjukkan rata-rata skor dari masing-masing observer pada setiap pertemuan. Uji reliabilitas pada pertemuan pertama diperoleh persentase 85,1 \%, pertemuan kedua memperoleh persentase 99,33\%, dan pertemuan ketiga memperoleh persentase $99,34 \%$. Keterlaksanaan pembelajaran menunjukkan bahwa media pembelajaran sangat baik . media pembelajaran dapat mempengaruhi pemahaman materi pada siswa. Berdasarkan hasil penelitian menunjukkan bahwa ada pengaruh penggunaan media pembelajaran terhadap proses pembelajaran pada kelas V SD Negeri Kenteng dimasa pandemi Covid 19. pembelajaran dengan menggunakan worksheet lebih baik dibandingkan dengan menggunakan LKS pada sebelumnya serta materi pembelajaran lebih mudah dipahami oleh peserta didik. Hasil penelitian ini juga sesuai dengan penelitian yang dilakukan Asrizal et al (2017), Bujuri \& Baiti, (2018), Khairani et al (2017), dan Komalasari et al (2019).

Media pembelajaran dikatakan layak apabila memenuhi kualitas isi dan tujuan pembelajaran, kualitas instruksional, dan kualitas teknis. Kualitas isi dan tujuan terdapat beberapa kriteria yang sesuai dengan komponen kelayakan isi. Kualitas instruksional sebagian ada yang sesuai dengan komponen kelayakan bahasa. Kualitas teknis terdapat kriteria yang sesuai dengan komponen kelayakan penyajian (Arsyad, 2019). Ditunjukkan dalam hasil respon peserta didik pada uji coba terbatas dan uji coba luas menunjukkan respon peserta didik pada yang telah diberikan media pembelajaran worksheet sangat baik. Pemilihan media worksheet sangat sesuai dan membantu untuk proses pembelajaran di era pandemi Covid-19 demngan materi lebih mudah dipahami dan diingat.

\section{KESIMPULAN}

Worksheet Berbasis Keterampilan Proses dan Karakter Pada Tema 8 Lingkungan Sahabat Kita Kelas V yang dikembangkan menggunakan metode $A D D I E$ telah menghasilakan sebuah produk yang layak untuk digunakan di SD . Worksheet ini dibuat guna untuk membantu pemahaman materi siklus air bagi peserta didik kelas V SD Negeri Kenteng. Setelah melalui tahap validasi media pembelajaran worksheet layak digunakan pada pembelajaran di Sekolah Dasar.

\section{DAFTAR PUSTAKA}

Anshory, I., Saputra, S. Y., \& Amelia, D. J. (2018). Pembelajaran tematik integratif pada kurikulum 2013 di kelas rendah SD Muhammadiyah 07 Wajak. JINoP (Jurnal Inovasi Pembelajaran), 4(1), 35-46.

Arsyad. (2019). Media Pembelajaran. Depok: PT. Raja Grafindo Persada

Asrizal, A., Festiyed, F., \& Sumarmin, R. (2017). Analisis kebutuhan pengembangan bahan ajar ipa terpadu bermuatan literasi era digital untuk pembelajaran siswa SMP kelas VIII. Jurnal Eksakta Pendidikan (JEP), 1(1), 1-8.

Bujuri, D. A., \& Baiti, M. (2018). Pengembangan Bahan Ajar IPA Integratif Berbasis Pendekatan Kontekstual. TER AMPIL: Jurnal Pendidikan dan Pembelajaran Dasar, 5(2), 184-197.

Hakim, I. N. (2014). Pembelajaran tematik-integratif di SD/MI dalam kurikulum 2013. INS ANIA: Jurnal Pemikiran Alternatif Kependidikan, 19(1), 46-59.

Hakim, D. L. (2017). Pelatihan Pembuatan Bahan Ajar Matematika Media Prezi. UNES Journal of Community Service, 2(2), 157-163.

Hasyda, S. (2020). Penerapan Metode Pembelajaran Discovery dalam Meningkatkan Prestasi Belajar IPA Pada Peserta Didik Kelas IV di Sekolah Dasar. Jurnal Pendidikan Dasar Flobamorata, 1(1), 6-13.

Khairani, S., Asrizal, A., \& Amir, H. (2017). Pengembangan Bahan Ajar Ipa Terpadu Berorientasi Pembelajaran Kontekstual Tema Pemanfaatan Tekanan Dalam Kehidupan Untuk Meningkatkan Literasi Siswa Kelas VIII SMP. Pillar of Physics Education, 10(1).

Komalasari, B. S., Jufri, A. W., \& Santoso, D. (2019). Pengembangan bahan ajar IPA berbasis inkuiri terbimbing untuk meningkatkan literasi sains. Jurnal Penelitian Pendidikan IP A, 5(2), 219-227. 
Murniyetti, dkk. (2016). Pelakasanaan Pendidikan Karakter Terhadap Siswa Sekolah Dasar. Jurnal Pendidikan Karakter, 163.

Pamungkas, A., Subali, B., \& Linuwih, S. (2017). Implementasi model pembelajaran IPA berbasis kearifan lokal untuk meningkatkan kreativitas dan hasil belajar siswa. Jurnal Inovasi Pendidikan IPA, 3(2), 118 127.

Prasetyono, R. N., \& Trisnawati, E. (2018). Pengaruh pembelajaran IPA berbasis empat pilar pendidikan terhadap kemampuan berpikir kritis. JIPV A (Jurnal Pendidikan IPA Veteran), 2(2), 162-173.

Sa'ria, S. Ngazizah, N. Adhe, L. 2021. Penilaian Keterampilan Proses Siswa Dalam Pembelajaran Daring

Susilowati, S. (2017). Pengembangan bahan ajar IPA terintegrasi nilai Islam untuk meningkatkan sikap dan prestasi belajar IPA siswa. Jurnal Inovasi Pendidikan IPA, 3(1), 78-88.

Wandini, R. R. (2017). Integrasi Pendidikan Karakter dalam Pembelajaran Tematik. Nižbamiyah, 7(2).

Warsiki, N. M. (2018). Penerapan Metode Pembelajaran Discovery Meningkatkan Prestasi Belajar Ipa. Jurnal Imiah Pendidikan Dan Pembelajaran, 2(3), 287-294.. 